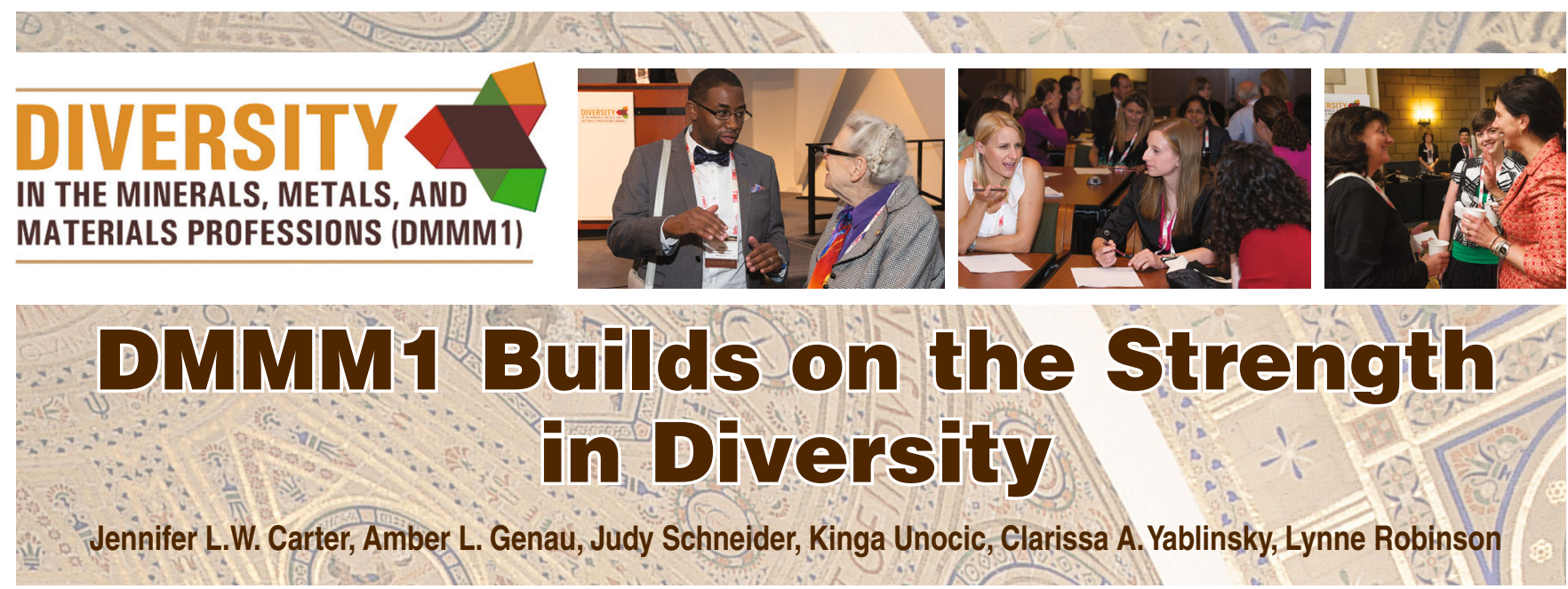

They shared stories, identified strategies that worked, and found common ground with colleagues representing markedly different backgrounds and experiences. To Elizabeth Holm, TMS Past President and organizing chair of the First TMS Summit on Creating and Sustaining Diversity in the Minerals, Metals, and Materials Professions (DMMM1), the 120 summit attendees also had a responsibility to carry the momentum forward to make diversity happen in their own work environments. She made this clear in her closing remarks on the final day of the event.

"I have two demands of you," she said. "First, commit to go home and advocate with your boss for one of the good ideas you've heard during the summit. If we each do that with one idea, more than 100 ideas will spread throughout the rest of the community. Second, commit to follow up with one person you've met here. Do something to continue the network that we've started."

DMMM1 attendees had quite a few ideas to choose from to fulfill Holm's charge. The summit's rather complex agenda of keynote presentations, panel discussions, and facilitated workshops yielded a rich tapestry of perspectives from all points of the career path - from assistant professors, to technical leaders at national laboratories, to industry executives. Several key themes did emerge, offering guidance to summit attendees in implementing what they learned, as well as to TMS and the greater scientific and engineering community in building a more inclusive professional culture. In the broadest terms, these themes include:
- Leaders at the highest levels must create the culture and - most importantly - take actions directly themselves. They cannot and must not simply assign the task to others or in any way delegate it and forget it.

- Mindful recruiting attentive to diversity issues is essential.

- Diversity does not come naturally. Policies, training, and support structures need to be developed and maintained to keep them vibrant, at all levels. No organization, department or individual group can simply check the box for diversity and believe that the work is done.

- It's time to move past a diversity "numbers" game to focus on creating an inclusive workplace. It's not enough for an organization to declare that it has the "right" number of each underrepresented group. The work environment must truly support a welcoming, inclusive culture.

While identifying guiding principles in addressing diversity challenges is important, DMMM1 organizers also made it their mission to distill what was learned into a practical "toolkit" of concrete action steps, novel and tested strategies, and effective recommendations. This toolkit - as well as the full report of what was shared at the summit and downloads of key presentations - is available to all in the "Resources" section of the summit website at www.tms.org /diversitysummit. TMS also invites all interested persons to join its new "Diversity in the Minerals, Metals, and Materials Professions" LinkedIn group to continue the conversation or get a new one started.

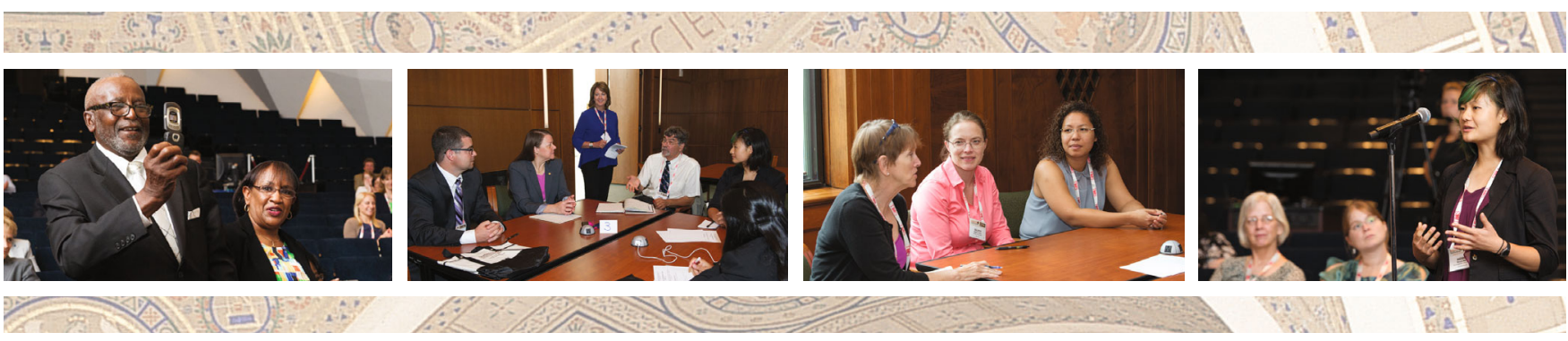


For further inspiration in making a difference in diversity, read the essays on the next few pages on the DMMM1 experience, submitted by the recipients of the TMS Women in Materials Science and Engineering Committee travel grants, funded by the TMS Foundation.

While reading of others' experiences is not the same as being there, their stories do offer a glimpse into the energy that was harnessed over three days in late July to make diversity a fact of life in science and engineering, rather than a challenge to overcome.

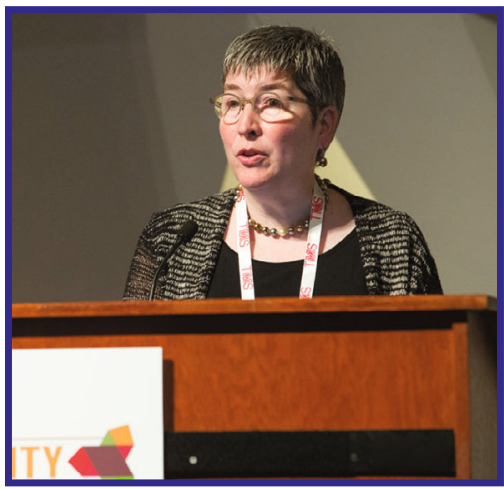

Elizabeth Holm, TMS Past President and professor, Carnegie Mellon University, chaired the summit organizing committee.

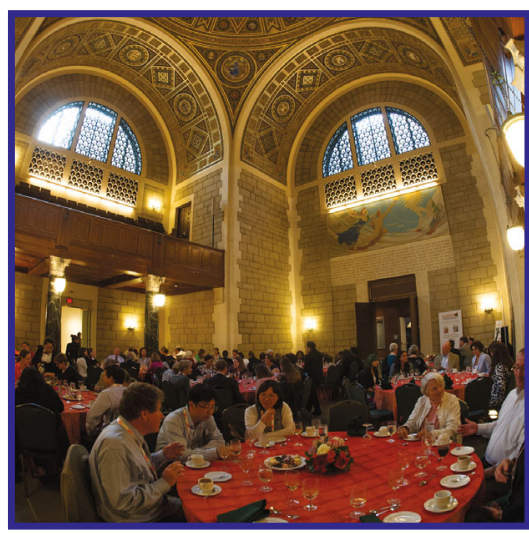

The historic National Academy of Sciences Building offered a beautiful and inspiring setting for DMMM1.

\section{Partners in Progress}

TMS thanks the following organizations for their support in making DMMM1 possible:

\section{Co-Sponsors:}

- American Institute of Mining, Metallurgical, and Petroleum Engineers

- Department of Energy, Basic Energy Sciences

- National Academy of Engineering

- Society for Mining, Metallurgy \& Exploration

- Society of Women Engineers

\section{Corporate Partners:}

- Battelle

- Newmont

- Caterpillar

- Ford

- GM

- TimkenSteel Corporation

\section{Viola Acoff Receives First TMS Diversity Award}

A highlight of the summit was the presentation of the first Ellen Swallows Richards Diversity Award to Viola Acoff, Associate Dean for Undergraduate and Graduate Programs and Professor, Metallurgical and Materials Engineering at the University of Alabama, Tuscaloosa. The award was made possible through a generous donation to the TMS Foundation by Jeffrey Wadsworth, chief executive officer and president, Battelle Memorial Institute, and his wife, Geraldine McCulley Wadsworth. Acoff's acceptance speech capped an evening of celebration that featured presentations on the life and legacy of Ellen Swallow Richards by Barbara Arnold, president, PrepTech, and Pamela Swallow, Richards's biographer and first cousin, three generations removed. For additional information and nomination criteria for the Ellen Swallow Richards Diversity Award, visit the TMS Honors and Awards Program website at awards.tms.org.

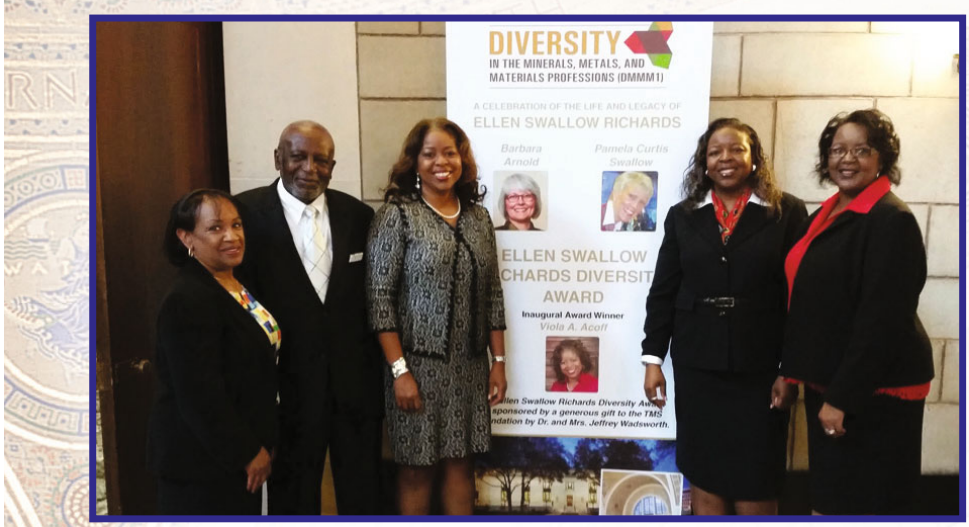

(Above): Cheering Acoff on during the awards presentation was her family. From left: Deborah Acoff, step-mother; Roosevelt Acoff, Sr., father; Viola Acoff; and sisters, Valerie L. Acoff and Cassandra R. Acoff.

(Right): Viola Acoff accepts her award from Jeffrey Wadsworth, Chief Executive Officer and President, Batelle Memorial Institute, with Hani Henein, TMS President, looking on.

Viola Acoff gives her acceptance speech.
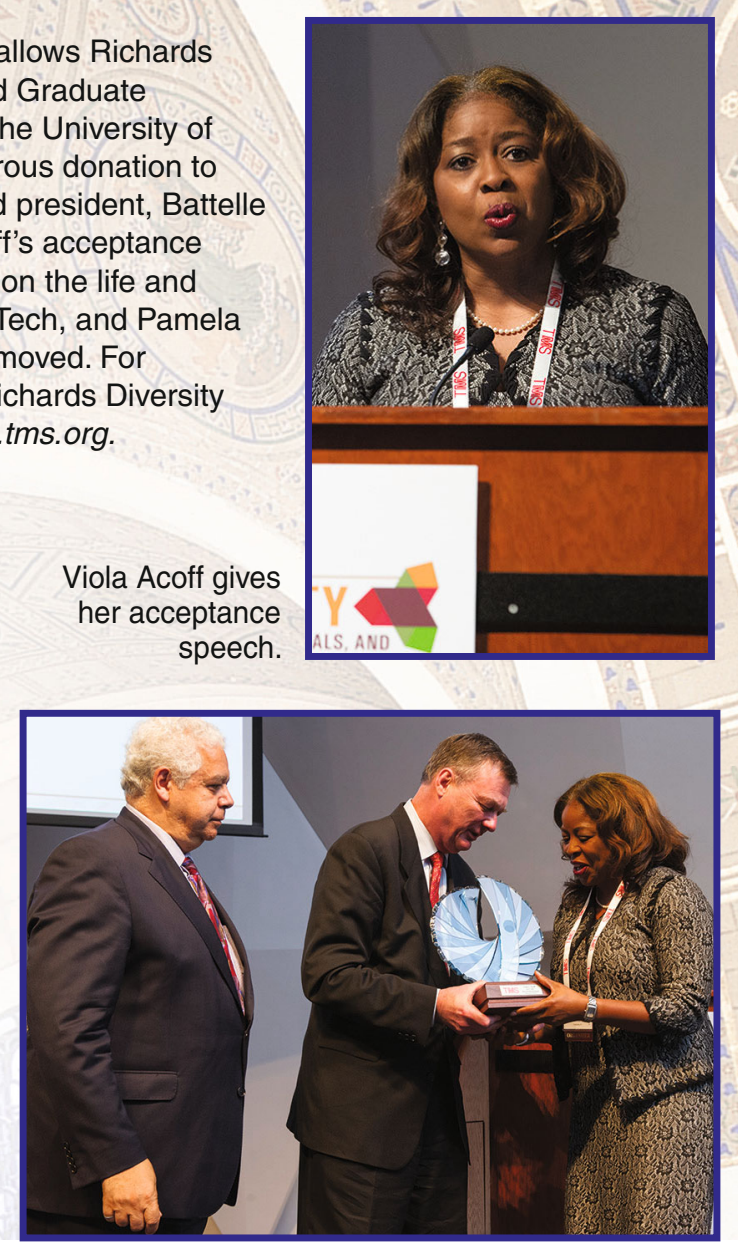


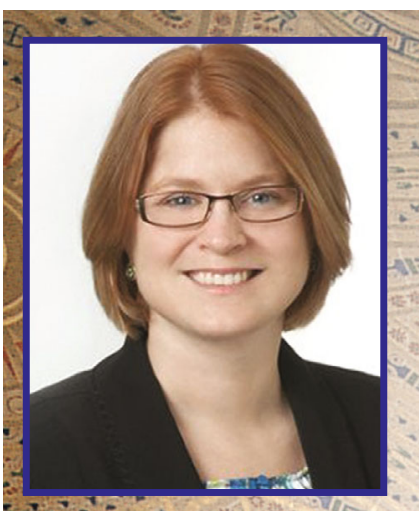

DMMM1 was organized and presented in what will hopefully be a timely opportunity to help change the profession. The onslaught of recent articles on sexual harassment in higher education and how workplace culture is a major obstacle for creating an inclusive workforce in science and engineering have brought these issues to the attention of the larger community. DMMM1 was a unique opportunity to discuss and brainstorm best practices that individuals and organizations could implement to promote inclusion in the minerals, metals, and materials professions.

The history of progress that the engineering profession has made in promoting diversity was an interesting presentation. While this advancement has been statistically significant, its effect on the lives of individual scientists has been prodigious. It was obvious to me that we have made some strides in including diversity of gender, but our ability to make great strides in promoting diversity of ethnicity really hinges on the broader issues of $\mathrm{K}-12$ education. There is a tremendous need for best practices that promote inclusion and diversity at the $\mathrm{K}-12$ level, as this shapes the future pipeline of the STEM (science, technology, engineering, and mathematics) fields. At the professional level, better practices are needed to promote international collaborations. Industries may have many ideas to share since their success is based on international

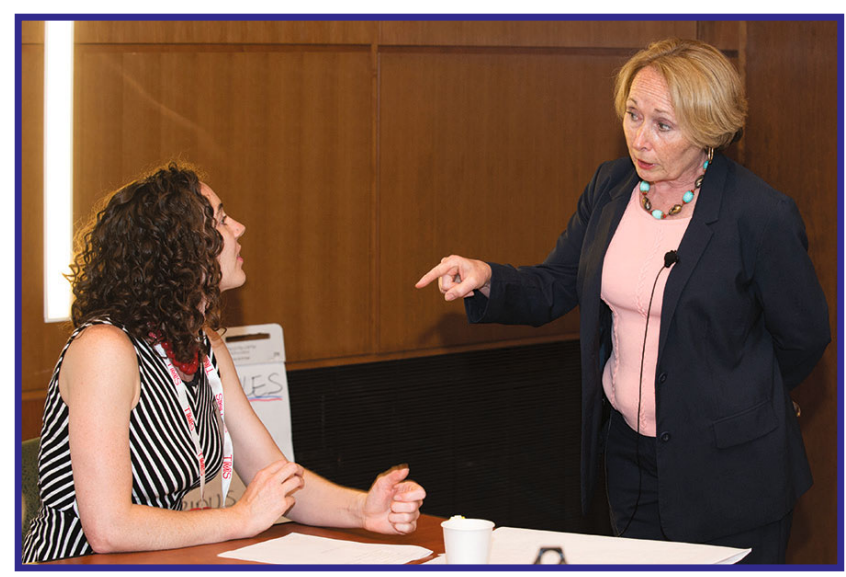

Internationally recognized author Valerie Young (right, standing) led a lively professional development session on overcoming the "imposter syndrome."

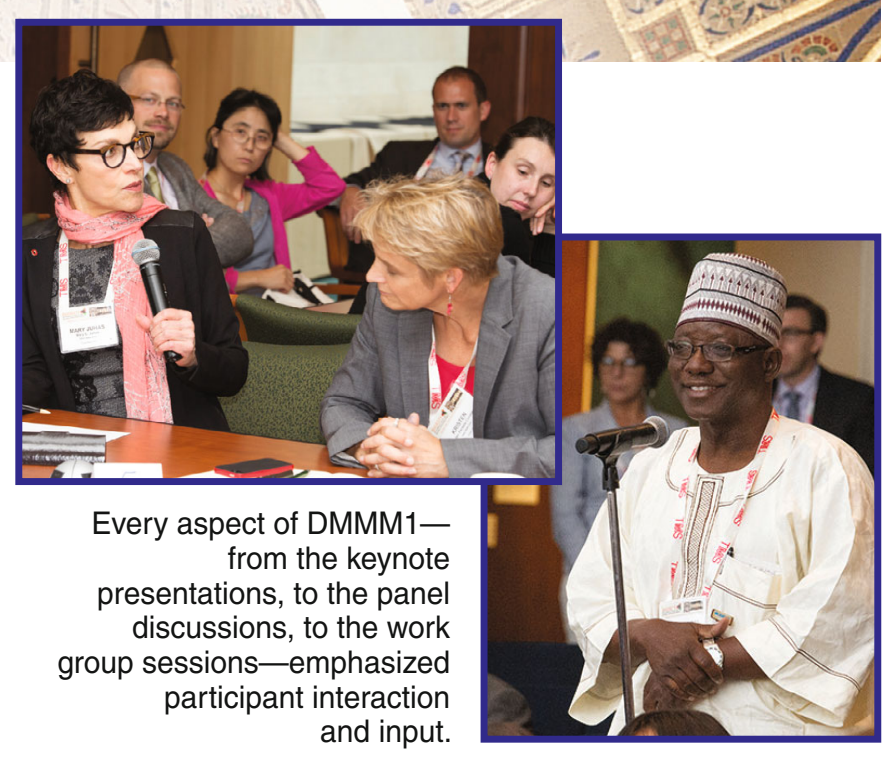

presence. In this regard, the summit provided a wonderful forum for identifying areas that would benefit from future brainstorming. One area in particular that stands out would be future DMMM1-related workshops to identify best practices for promoting international diversity.

The breakout discussions really brought home the message that everyone is responsible for promoting an inclusive work environment. Organizations need to take steps to develop policies that promote inclusion. Individuals have the responsibility to foster a culture of inclusion and diversity of thought. I was impressed and heartened by the number of participants that were in positions to promote inclusion in their organizations.

The most useful session I attended was the professional development session on identifying cultural patterns. This moved beyond trite stereotypes and really addressed how cultural patterns have arisen from religious and societal expectations, how these patterns change, and how different cultures react to business-related scenarios. The insights presented were really helpful for developing successful collaboration.

The major takeaway for me was to continue to question what I can do, in the words of Mahatma Gandhi, to "be the change you wish to see in the world." In particular, what can I do as a TMS member and volunteer to promote inclusion in my professional organization? 


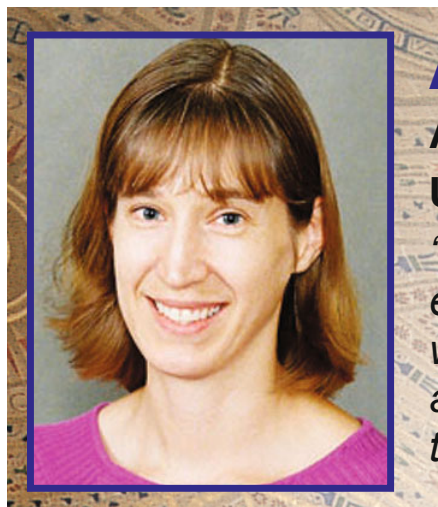

Amber Li Genau

Assistant Professor

University of Alabama, Birmingham

"It is my great hope that we will reach the point in engineering where there is room in our profession for all women, and not just those who have both the highest ability and a willingness to make the sacrifices necessary to be extraordinary."

I experienced DMMM1 as a collection of statistics and stories. Those of us in attendance heard a lot of numbers trying to capture the state of diversity within the materials community, and in STEM fields more generally. We also heard inspiring stories of women and men who overcame adversity and prejudice to become highly successful in their fields. What follows are some of the statistics and stories that struck me the most. In large part, they reflect my identity as a white woman working in academia.

The story of Ellen Swallow Richards, the summit honoree, is truly exceptional. But it wasn't necessary to go back to the 19th century to hear stories of women overcoming long odds. Plenary speaker Corale Brierley, current vice president of the National Academy of Engineering (NAE), has had a decorated career in extractive metallurgy. She spoke about her early life on a sheep ranch in rural Montana, attending school in a one-room schoolhouse. Mildred Dresselhaus, renowned Massachusetts Institute of Technology (MIT) professor and the third woman ever to be inducted into the NAE, spoke with great enthusiasm and joy about the challenges to be solved in a scientific career. She described being born "on the wrong side of the tracks" in the Bronx, and writing away for mail order exams (delivered without the answer keys) to supplement the substandard education provided by her neighborhood schools. Martha Goodway graduated from the Massachusetts Institute of Technology in 1957, 84 years after Ellen Swallow became the first woman to accomplish that feat. On graduation day, as Martha crossed campus in her cap and gown, a professor stopped and told her that, in his opinion, women still did not belong at the institute. It took Martha 12 years, but she was eventually offered her dream job as metallurgist at the Smithsonian Institution, a position she held for more than four decades.

Some of the statistics we heard were mildly encouraging. In the last decade, the number of female faculty members in engineering departments has increased from $8.9 \%$ to $14 \%$, although the number of women completing bachelor's degrees in engineering is virtually unchanged. Mary Galvin, Director, Division of Materials Research, National Science Foundation (NSF), showed a chart indicating that female PIs are actually slightly more likely to be funded by NSF than their male colleagues. While I think this graph was intended to be encouraging, what I (and all of the other assistant professors) noticed was the downward trend of both lines. The fact that funding rates have dropped from $40 \%$ to around $20 \%$ is going to have more impact on my career than the fact that being a woman gives me, statistically speaking, a $2.5 \%$ edge.

Linda Abriola, Dean of Engineering, Tufts University, and another NAE inductee, then talked about a study by the National Research Council that showed no gender discrimination in hiring and promotion decisions for STEM faculty members. In fact, female faculty who apply for jobs or tenure are again slightly more successful than their male colleagues. However, she also shared more "leaky pipeline" statistics: Of the women who complete Ph.D.s, a smaller percentage apply for faculty positions than their male counterparts, and a smaller percentage of female assistant professors go up for tenure. If there really is parity between men and women in hiring and promotion decisions, then this means that women must be opting out of their own accord.

It isn't so hard to see why this is. The funding situation is one reason. I can't count the number of senior faculty who have told me how glad they are not to be starting out in academia right now, because they don't think they could compete successfully. Another arresting statistic that Galvin shared from a University of California, Berkeley study was in the form of side-by-side

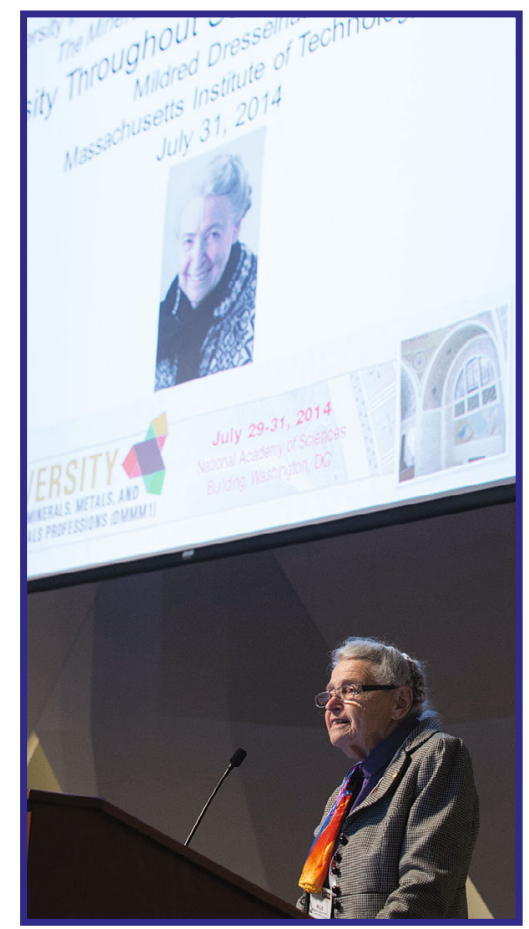

Mildred Dresselhaus offered an inspiring talk on the challenges and choices that she faced during her career and how these compare with contemporary experiences. 


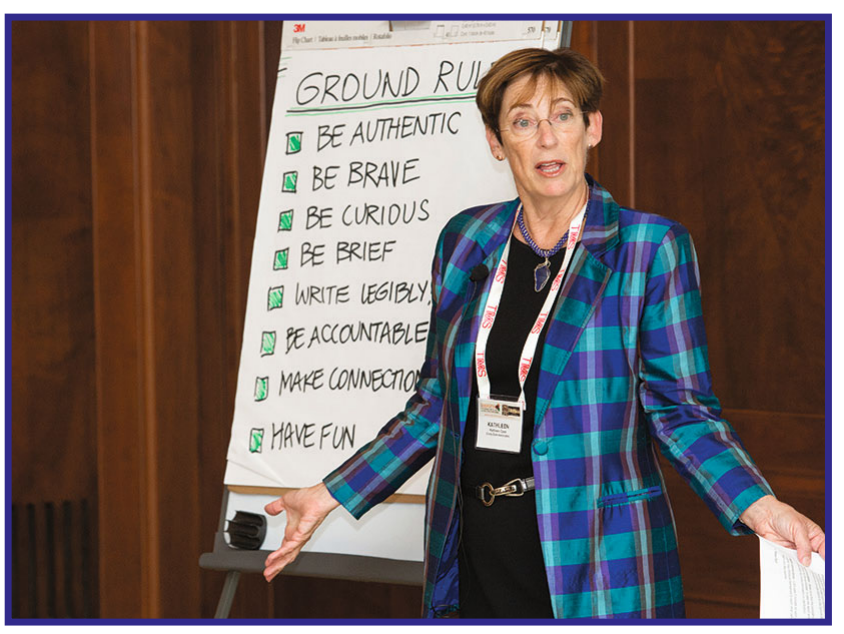

Facilitated working sessions focused on identifying actions that could be taken in advancing diversity and inclusion.

pie charts. Among tenured faculty members, $70 \%$ of men are married with children; only $44 \%$ of female faculty fall into that category. Unmarried, childless female professors outnumber their male coworkers in that demographic by more than 2 to 1 . And then there were the stories. During the Early Career breakout session, the topic that needed the most discussion time was if, when, and how to report sexual harassment. The number of women directly affected by the issue was a surprise to us all.

Being an engineer is hard, and being a female engineer is even harder. Implicit bias against women require those individuals who persist to be better than their male colleagues to achieve the same level of success. In one Swedish study, CVs with a woman's name on them had to be 2.5 times better than those from men to be rated the same for productivity and scientific competency. This held true regardless of whether the person doing the rating was a man or woman. Elizabeth Holm, the organizing force behind the summit, shared a wonderful story from her father. His wish, she said, is that women in engineering could be mediocre. Here's why I wholeheartedly agree: As a medical doctor, her dad saw that the first women to be accepted to medical school were always at the top of their class. They had to be. It was on their shoulders to prove that women belonged in medicine. Once the ratio of male to female medical students became roughly equal, female students showed the same distribution of performance as the men. Some were exceptional, most were average, and a few were, relatively speaking, mediocre.

After Mildred Dresselhaus finished speaking, she took questions from the audience. Carol Handwerker from Purdue University rose and recounted a story from Dresselhaus's life: One Friday while she was pregnant with one of her four children, she went to work in her lab at MIT as usual, then performed Friday evening with her music ensemble. She returned to work Monday morning, and was somewhat indignant that her male colleagues didn't notice that she'd given birth over the weekend. Her response to the summit audience was simply, "Well, yes. I had no choice." She reflected that she did what she had to do, and proved what could be done, but the balance she struck between her family and her career was an extreme one-one that she would not particularly recommend to other people or even the one that she would have chosen for herself. In order to stay in the field she loved, she didn't have a choice.

It is my great hope that we will reach the point in engineering where there is room in our profession for all women, and not just those who have both the highest ability and a willingness to make the sacrifices necessary to be extraordinary. The best way to achieve that goal is to bring more women (and members of other underrepresented groups) into engineering, but the statistics show that this is not happening on its own. It will require us to seriously re-envision the culture of engineering and academia. It will require training people to value differences and respect diversity. It will require change, particularly by those who have historically been best served by the status quo. Those are extraordinary challenges, but I would argue that, with the monumental challenges facing our profession, we cannot afford to do otherwise. Luckily, the stories from DMMM1 are a reminder that we are capable of extraordinary things.

As a final note: In its 50 year history, the National Academy of Engineering has inducted more than 3,600 people. The three members mentioned in this essay, along with summit organizer Tresa Pollack, place $4 \%$ of all women who have ever been admitted to the NAE in attendance at DMMM1. You do the math.

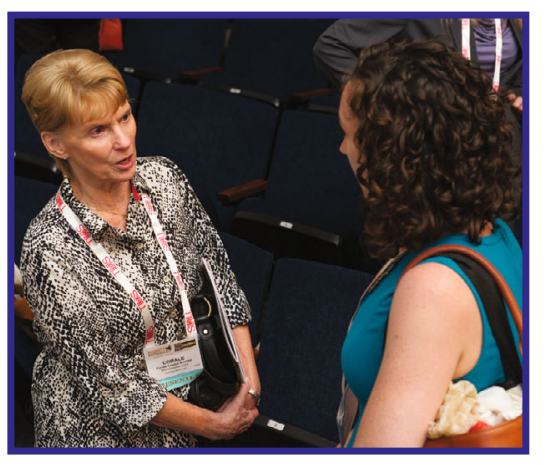

Corale L. Brierley (right), Vice President, National Academy of Engineering, gave opening remarks that traced her journey from a Montana sheep ranch to a distinguished career in extractive metallurgy.

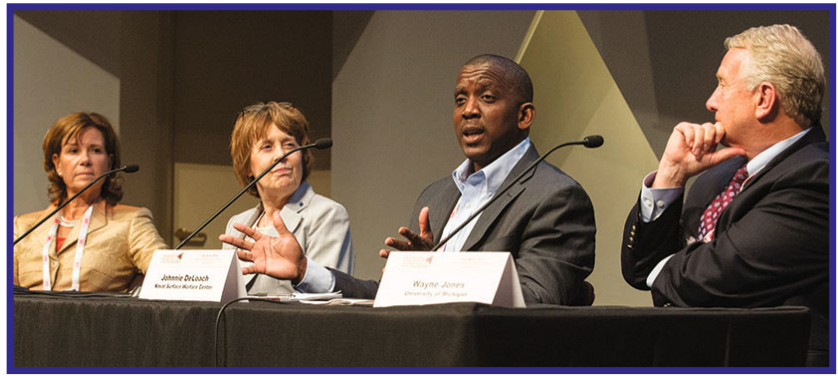

Summit keynote speakers (from left) Dawne Hickton, RTI International Metals; Linda Abriola, Tufts University; and Johnnie DeLoach, Naval Surface Warfare Center, explored commonalities and differences in their respective workplace sectors during the opening panel discussion. Wayne Jones, University of Michigan, moderated. 


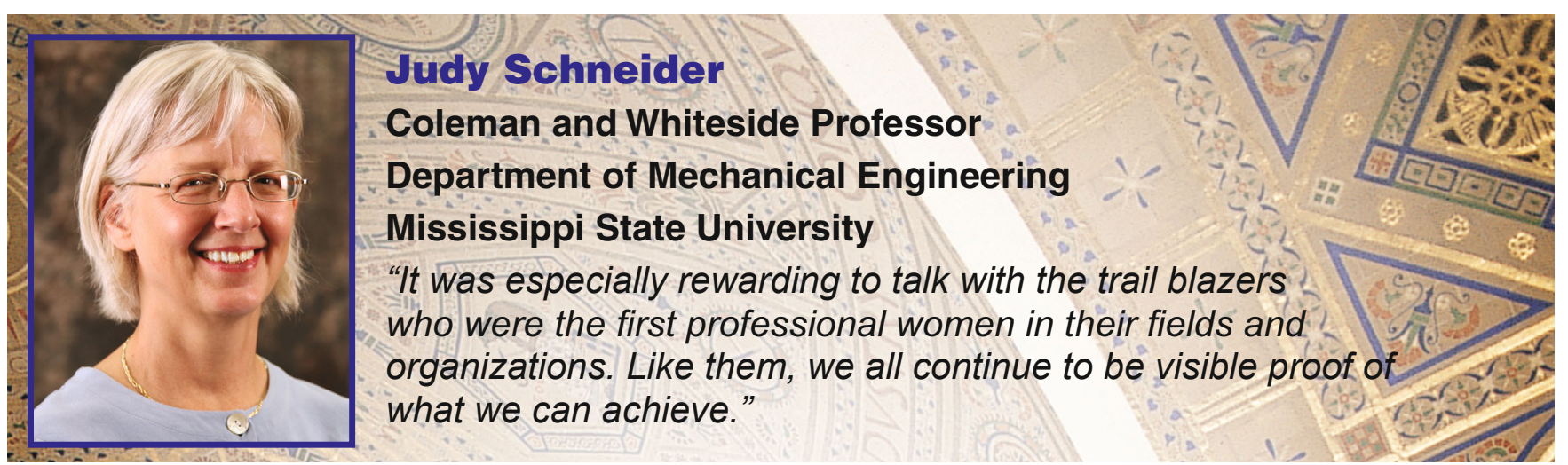

I was most honored to be able to attend DMMM1. The attendees and invited speakers provided a good overview of our professional careers with regards to where we have come from, where we are, and where we need to go in promoting diversity and inclusion. It was especially rewarding to talk with the trail blazers who were the first professional women in their fields and organizations. Like them, we all continue to be visible proof of what we can achieve. We owe them gratitude for paving the way and we must continue to do the same. I was impressed with the overwhelming drive that compelled all the attendees to become involved in the sciences because it is "just so interesting." I also found reassurance that the importance of what we do and what we are driven to do should not be diminished due to occasional obstacles encountered along the way.

I had never considered whether diversity or inclusion was more about the issue or about the culture. Do we need a critical mass in achieving our goals or do we need a culture of embracing differences? The emphasis often is with better representation of under-represented minorities, but everyone needs to feel included within the culture. If we can find ways to change the culture, then we can establish a way of thinking that embraces the critical mass desired. We need to work toward establishing a nurturing and welcoming environment by working with leaders to develop policies to improve climate. I was impressed by the number of department chairs and other upper level administrators who made time to attend. Perhaps, in the words of one of the plenary speakers, Johnnie DeLoach, Naval Surface Warfare Center, these leaders have already joined our choir.

DMMM1 provided a nice historical overview of the last 150 years. Many of us found humor in the optimistic predictions on the role of women in science and society made by Ellen Swallow Richards in the 1870s, who was honored by an award in her name at the summit. Although we hope that things would move faster, they haven't. Jules Verne wrote about going to the moon in 1865. But it wasn't until 1969, 104 years later, that Von Braun's team at NASA took us there. While the current 2014 status of the moon lists footprints, but no life habitats, the technology that has developed in that same time frame is helping us achieve more. When Mildred Dresselhaus talked about being born "on the wrong side of the tracks" and her efforts to cross those tracks, she did note that the internet would have helped. While we aren't living on the moon, we cannot overlook how that spin-off technology is helping folks "cross over the railroad tracks." The internet and Skype are examples of tools that can connect like-minded individuals from anywhere.

As educators and researchers, we should strive to incorporate these technologies to advance our own sphere of influence to include diverse thought.

This brings me to my favorite quote from the summit: "Don't ask why. Ask why not."

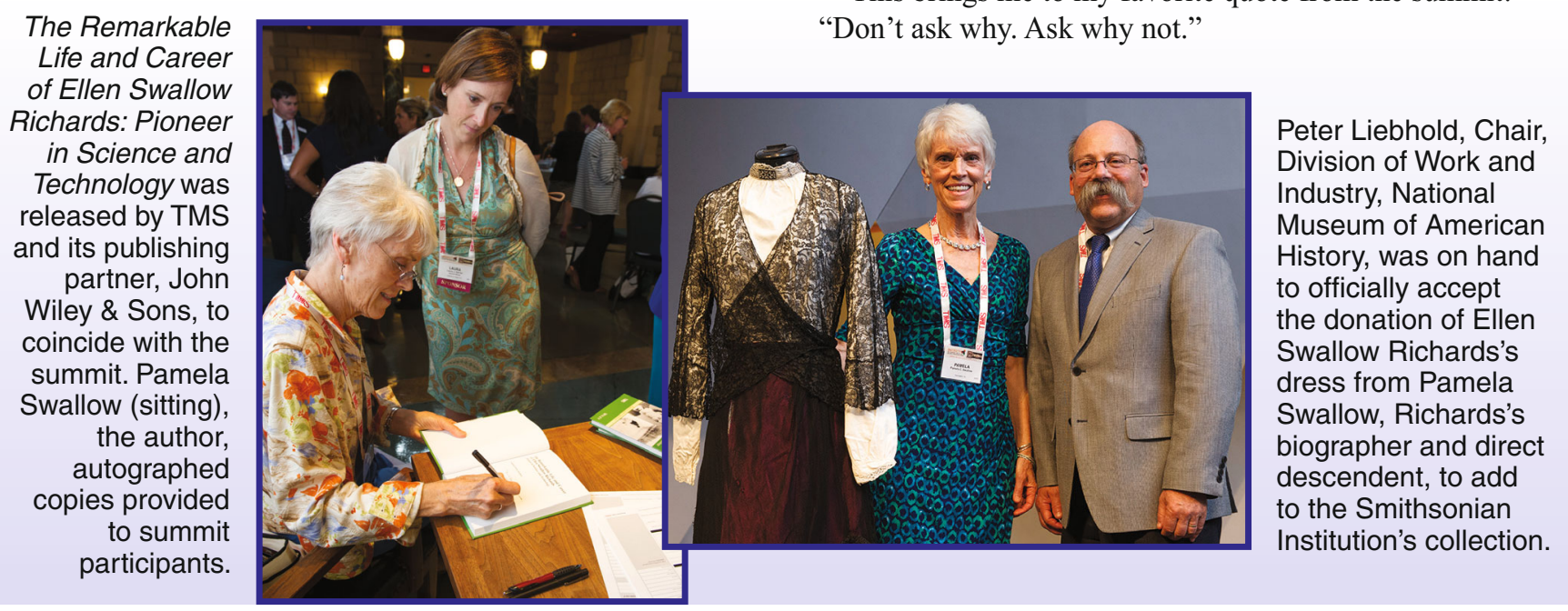




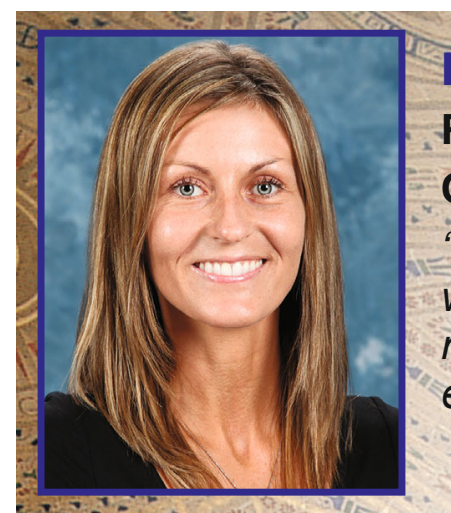

DMMM1 focused on what diversity in the workplace means and what the current challenges and opportunities that we, as a professional society, need to address. Overall, the meeting was well attended by a diverse group of professionals from academia, industry, and government institutions. There were also a number of well-accomplished keynote speakers who provided guidance on how to develop good leadership skills in order to be become successful. They talked about where we are in terms of minorities and diversity, when compared to databases from previous years. It has been recognized that there is a progress in incorporating diversity, but growth is slow. So, how can we improve it? I believe starting early, and reaching out to younger generations to make them more interested in a STEM education.

Part of the summit was dedicated to panel discussions followed by facilitated working sessions. The panelists shared their experience as established and proven leaders in their field. One subject that was highlighted several times was mentoring, which was recognized as an important and crucial part in everyone's career. As leaders, it is our responsibility to make sure we guide, mentor, challenge, and provide the necessary resources for young scientists and engineers to be productive and reach their goals,

Another aspect was to improve the pipeline in the STEM fields. This was mainly associated with universities, where professors should take the responsibility to produce the best and brightest students to meet the future needs for careers in science and technology. A number of companies have

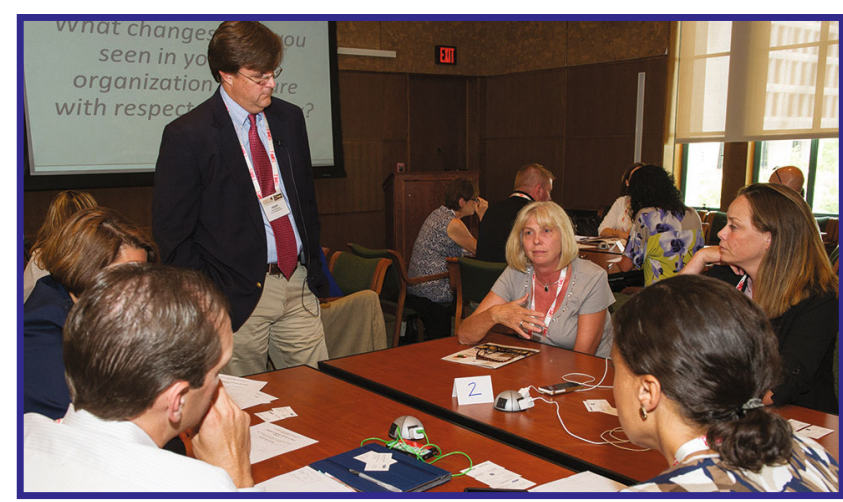

The summit working sessions were divided into government, academia, and industry sectors to focus discussion on the diversity issues unique to each workplace environment.
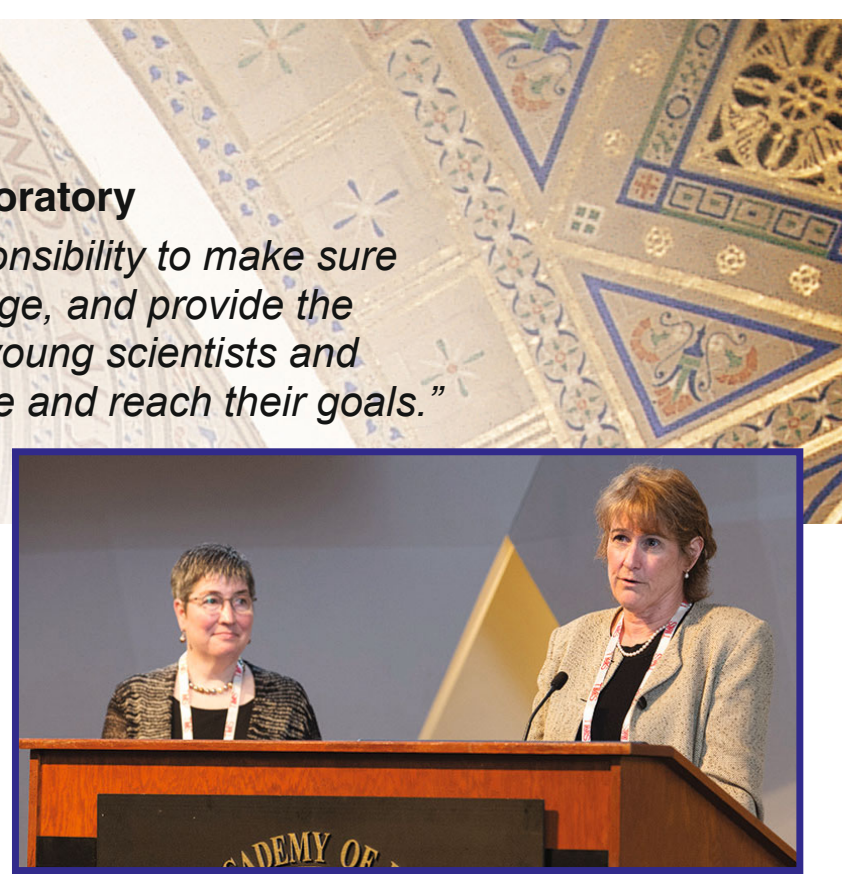

Elizabeth Holm (left) listens as Mary Galvin, National Science Foundation, responds to questions after presenting a statistical overview on the progress of diversity in research and academia.

requirements these days to include a diverse candidate pool and to provide equal opportunity to everyone. However, they often struggle with finding an adequate number of qualified candidates. It was pointed out and recognized that, at the end of the day, the best candidate for the position should be the one selected.

The topic of work-life balance was most challenging for the panelists. Everybody recognized that it is not always possible to balance work and life responsibilities all at the same time. At different stages of your life, one will be more favored than the other, depending on priorities, but you just have to keep trying and working on creating this balance. The main message is that it is up to the individual to decide what needs to be done at that moment to meet deadlines, parenting, and spouse responsibilities and expectations, while still meeting and exceeding career goals.

The Leadership Panel Discussion was my favorite because it was very informative and hosted outstanding speakers who sent the message that it "can all be done." As Dianne Chong from Boeing said, "You can have it all but not at the same time. But, when you look over the past 10 years it will look like you have it all."

Overall, it was a good experience to attend DMMM1 and to learn about the challenges that we face in our respective professions. The main take-home message that I received is that everybody should be made aware and be committed to creating diversity in the profession. Some of us might still ask "why diversity?" Part of that answer was stated by Linda Abriola, Tufts University, and one of the DMMM1 keynote speakers: "The quality of the product needs diversity of thoughts." 


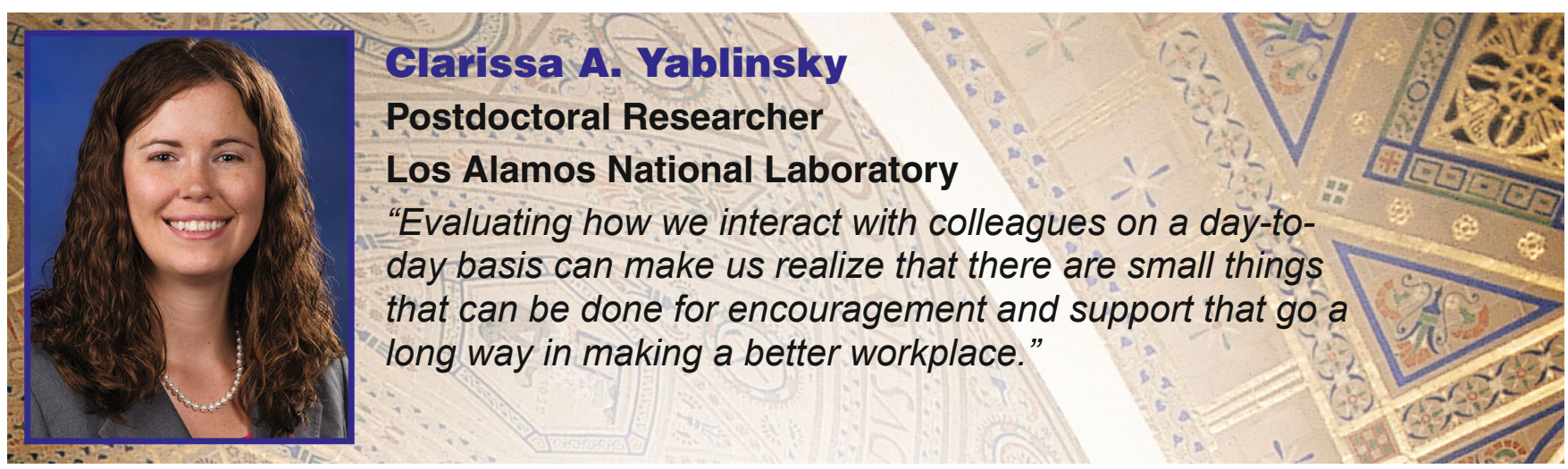

For being a two and a half day conference, DMMM1 was packed with information and great discussions. I wish I would have had some of these discussions earlier in my career, and I am glad to have a forum in which to have these discussions now. The meeting was really set up to help each person get the most out of it, with sessions for each of the employment sectors, as well as ones for different stages of your career, and two professional speakers on communications and the "imposter syndrome." I left the meeting with a few things that really stuck with me.

One of the continuing themes that came up throughout the summit was the necessity for strong mentoring. Many of the speakers and session leaders attributed their successes to having great mentors to help guide them and give them encouragement. However, it was unclear to some as to exactly what role a mentor should play. Repeatedly, it was mentioned that a mentor does not have to be someone you can talk to about personal matters. They can also be mentors in specific areas of your job. The key to having great mentors - and yes, you should have more than one (really as many as you can) is to understand exactly in what capacity each person can help you and your career. When you have a grasp on what mentor serves what role, you can start to collect advice and move on from there. One large take-away from the discussions on

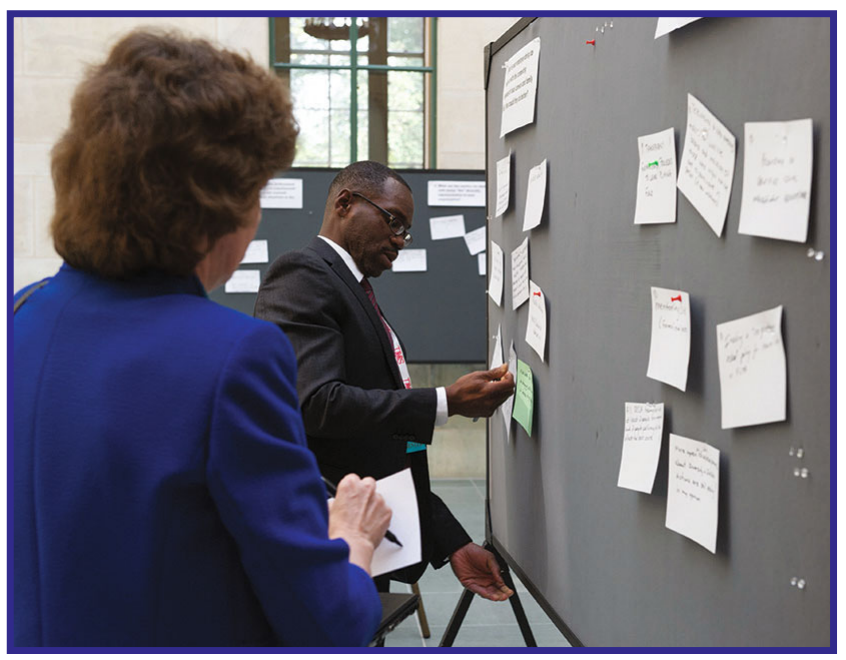

Summit participants were challenged to identify specific strategies and action steps for advancing diversity and inclusion in the workplace. mentoring was that you should never be discouraged when someone does not fill the role you wish them to play. Take a look around, find others to approach, and always be willing to ask for help in places that may not be obvious. Do not fall into the trap that mentors can only come from your institution. Too often, we can recede into our own worlds and forget that many people we have met along the way are part of our support and mentoring system as well.

I also found the breakout groups by employment sector a useful forum. Working for the government certainly has its own unique challenges. Shrinking budgets, remote laboratory locations, and flexibility in work-life balance options are all concerns at many national laboratories. Discussions covered such topics as hiring with consideration toward potential and not merely record and the need to highly value professional growth and development.

The biggest way we can help increase diversity is to be honest with the evaluation of progress toward a diverse work environment. In this way, policies and procedures can be put into place to clear the path to a diverse workplace. Some of the issues examined at the summit along these lines were: increasing the available candidate pool for hiring; getting consistent commitments to hire diversely in both entry-level and management positions; and having managers participate in diversity activities - not just send others in their place. It was noted a few times that the people attending the conference were already interested in the subject of diversity. However, we need to get everyone to participate and truly commit to diversity.

There were many other topics discussed that highlighted the ongoing and important challenges to diversity. Numbers in academia are collected more than in other sectors, and while these indicate that there has certainly been advancement, there is still a long way to go to have percentages equal to the population percentages. The improvement is certainly a step in the right direction, because being exposed to diverse faculty can change perceptions of diversity in the workplace. Another challenge is simply to sustain ongoing action. Evaluating how we interact with colleagues on a day-to-day basis can make us realize that there are small things that can be done for encouragement and support that go a long way in making a better workplace. Going forward, I am encouraged by the ongoing conversation, but there is still much work to be done.

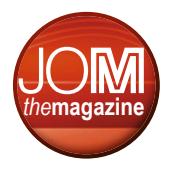

